\title{
Tidal variation of total suspended solids over the Yangtze Bank based on the geostationary ocean color imager
}

\author{
Yu ZHOU ${ }^{1}$, Jiliang XUAN ${ }^{1} \&$ Daji $\mathrm{HUANG}^{1,2^{*}}$ \\ ${ }^{1}$ State Key Laboratory of Satellite Ocean Environment Dynamics, Second Institute of Oceanography, Ministry of Natural Resources, \\ Hangzhou 310012, China; \\ ${ }^{2}$ Key Laboratory of Conservation and Restoration of Tropical and Subtropical Marine Natural Resources, Fourth Institute of Oceanography, \\ Ministry of Natural Resources, Beihai 536000, China
}

Received December 17, 2019; revised April 5, 2020; accepted April 21, 2020; published online June 16, 2020

\begin{abstract}
Hourly mapping by a Geostationary Ocean Color Imager was used to reveal the spatial pattern and tidal variation of total suspended solids (TSS) over the Yangtze Bank in the Yellow and East China Seas during the winter. The TSS form a tongueshaped structure, which decreases further offshore in a stepwise manner. The stepwise change is separated by two fronts of TSS, which are located near the $20-\mathrm{m}$ and $50-\mathrm{m}$ isobaths. The tidal variation of TSS concentration during the study period is evident and can be divided into three stages: decay, maintenance, and growth. Compared with the relatively stationary TSS during the maintenance stage, drastic changes exist during the decay and growth stages. In terms of tide-induced mixing, the dynamic analysis shows that both the topography and the tidal currents play an important role in the spatio-temporal variation of TSS during the tidal period. In particular, spatial distribution is primarily determined by the topography, whereas the temporal variations in tidal scale are determined by the tidal currents.
\end{abstract}

Keywords Yangtze Bank, Total suspended solid (TSS), Particle concentration, Tidal variation, Tide-induced mixing

Citation: Zhou Y, Xuan J, Huang D. 2020. Tidal variation of total suspended solids over the Yangtze Bank based on the geostationary ocean color imager. Science China Earth Sciences, 63: 1381-1389, https://doi.org/10.1007/s11430-019-9618-7

\section{Introduction}

The Yangtze Bank is a flat and broad shallow water, located at the junction of the Yellow Sea and the East China Sea, with an average depth of $26 \mathrm{~m}$ (Figure 1). A large amount of land sediment discharge as well as the resuspension of bottom sediment caused by strong tide-induced mixing, make the Yangtze Bank one of the most turbid coastal areas in the world (Milliman and Meade, 1983; Saito and Yang, 1995; Shi and Wang, 2010). The level of suspended sediment over the Yangtze Bank is generally higher along the coast than in the open sea and higher in the winter than in the summer. The area from the Yangtze River Estuary to the coast of Jiangsu is

\footnotetext{
* Corresponding author (email: djhuang@sio.org.cn)

(C) The Author(s) 2020
}

highly turbid throughout the year. The suspended sediment over the Yangtze Bank demonstrates evident seasonal variation, reaching the maximum in winter, forming a special tongue-shaped structure, and decreasing offshore in a stepwise manner (Figure 1) (Yuan et al., 2008; Shi and Wang, 2010; Bian et al., 2013). The movement and distribution of suspended sediment directly affects the hydrodynamic and ecological environment of the Yangtze Bank (Klemer and Barko, 1991; Chen, 2001; Mutshinda et al., 2013; Zhou et al., 2017). Therefore, understanding the spatio-temporal variation and the dynamics of suspended sediment in this area is essential for multi-disciplinary researchs.

Previous studies on the spatio-temporal characteristics of suspended sediment over the Yangtze Bank demonstrated that the suspended sediment exhibits obvious seasonal and 


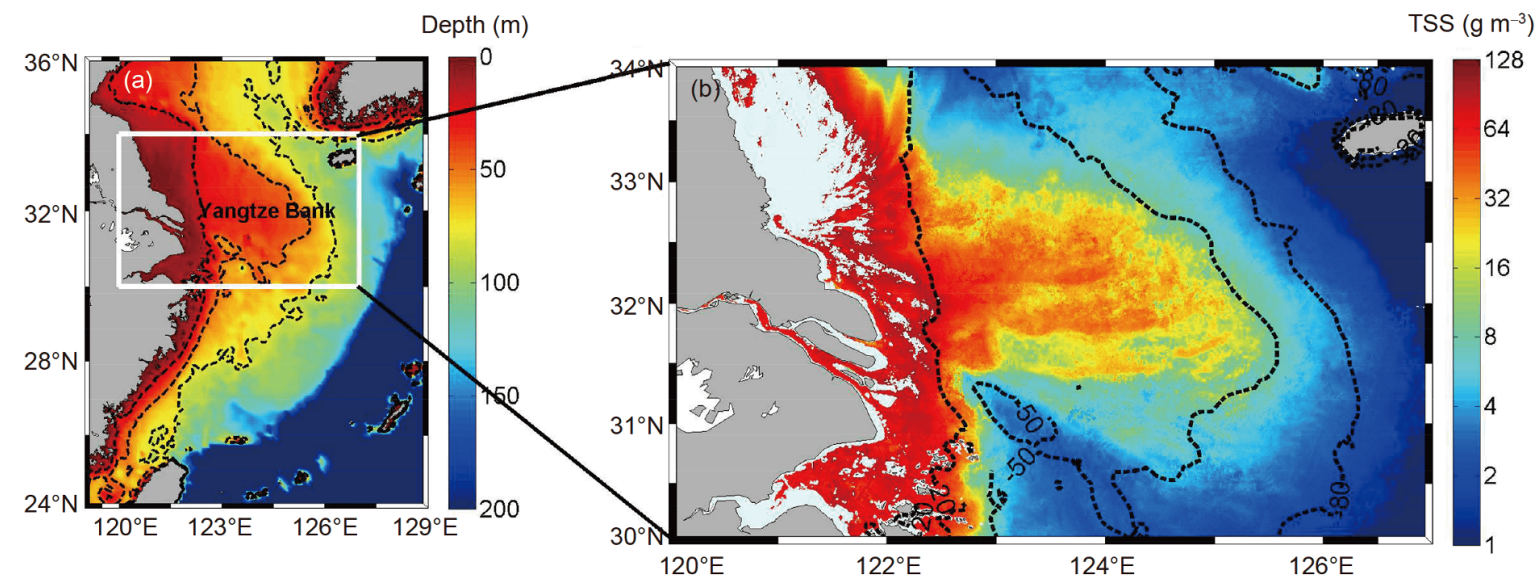

Figure 1 (a) Study area and sea floor topography; the white box indicates the study area $\left(30^{\circ} \mathrm{N}-34^{\circ} \mathrm{N}, 120^{\circ} \mathrm{E}-127^{\circ} \mathrm{E}\right)$. (b) Total suspended solids based on the geostationary ocean color imager in February 2016; the black lines are 20-, 50-, and 80-m isobaths.

short-term variation (spring-neap tidal cycle and synoptic scale). These characteristics are modulated by multi-scale hydrodynamic forcing (runoff, wave, tide) and atmospheric forcing (wind, air temperature) (Yuan et al., 2008; Shi and Wang, 2010; Yuan and Hsueh, 2010; Shi et al., 2011; Bian et al., 2013; Luo et al., 2017; Qiao et al., 2017).

Through in-situ and remote-sensing observation, researchers found that the suspended sediment over the Yangtze Bank changes seasonally and is higher in the winter than in the summer. Many researchers (Shi and Wang, 2010; Bian et al., 2013) believe that the increased level of suspended sediment in winter in primarily due to strong vertical mixing, which is the destruction of stratification by strong winds and cooling during the winter, in combination with the resuspension of bottom sediment caused by bottom shear stress. This process diffuses the higher suspended sediment from bottom to the surface through vertical mixing. Some researchers (Yuan et al., 2008) also believe that the eastward cross-shelf movement of high-turbidity water results in a high concentration of suspended sediment during the winter. Luo et al. (2017) used a numerical model to simulate the three-dimensional (3-D) hydrodynamic conditions and migration process of suspended sediment over the Yangtze Bank, thereby verifying the hypothesis that the bottom shear stress controls the local suspended sediment.

In addition to seasonal variation, Chen (2001) and Shi et al. (2011) found that the suspended sediment over the Yangtze Bank also exhibited evidence of spring-neap tidal variation. The suspended sediment concentration during spring tides is approximately 1.5-2.5 times as large as that during neap tides in the winter. However, due to limitations in the spatiotemporal resolution of observational data, a detailed description of the spatial pattern and tidal variation of suspended sediment has not yet been reported.

In this study, total suspended solids (TSS) particle concentration data from the high spatio-temporal resolution
Geostationary Ocean Color Imager (GOCI) were used to analyze the spatio-temporal variations of TSS over the Yangtze Bank (GOCI-TSS). The temporal sampling interval of GOCI data is one hour (eight times per day, from 08:16 to $15: 16$, UTC +8 ), and the spatial resolution is $500 \mathrm{~m}$, which is sufficient to meet the needs of researches of short-term variations in TSS (Ryu et al., 2012). After scanning the available GOCI-TSS data from 2013 to 2019, we were fortunately able to find continuous cloud-free images from 08:16 to $15: 16$ on February 8, 2016. Based on these images, the spatial distribution of TSS over the Yangtze Bank, as well as its tidal variation characteristics, were quantitatively analyzed. In addition, the dynamic mechanism of the spatiotemporal variation of TSS was also investigated, together with observed TSS and the reconstructed tide results predicted by the Finite Volume Coastal Ocean Model (FVCOM).

\section{Materials and method}

\subsection{Hourly TSS data from the GOCI}

This study used the hourly GOCI-TSS images provided by the Korea Ocean Satellite Center (KOSC), which demonstrate the advantage of high spatio-temporal resolution. The spatial resolution is $500 \mathrm{~m}$, and the temporal sampling interval is one hour (eight times per day, from $08: 16$ to $15: 16$, UTC+8). Research by Choi et al. (2014) and Doxaran et al. (2014) showed that GOCI-TSS data can also be applied to near-shore high-turbidity waters, and Yin and Huang (2016) used GOCI-TSS data to describe a complete life cycle of the submesoscale coastal frontal waves in the East China Sea. Therefore, using this data to study the short-term spatiotemporal variation of TSS over the Yangtze Bank is reliable.

Because the Yangtze Bank is usually covered by heavy clouds, it is difficult for the GOCI to provide cloud-free 
images for the continuous $12.4 \mathrm{~h}$ period required to research the variation of TSS during a complete tidal cycle. Following the long-term observation of GOCI-TSS images between 2013 and 2019, the period from 08:16 to 15:16 on February 8,2016 was selected, as it was the longest period of almost cloud-free images. We used the GOCI Data Processing System (Ryu et al., 2012) to process the Level-1B emissivity products (eight times per day, from 08:16 to 15:16) into Level-2 TSS products, as the KOSC only provides Level-2 TSS products three times a day, from 10:16 to $12: 16$, and then removes the data points with a value greater than $100 \mathrm{~g} \mathrm{~m}^{-3}$ or less than (or equal to) $0 \mathrm{~g} \mathrm{~m}^{-3}$. At the same time, the gradient-based frontal outline method (Yin and Huang, 2016) was applied to extract frontal outlines six times per day (from 09:16 to 14:16). However, the TSS images captured at 08:16 and 15:16 could not extract the frontal outlines due to insufficient spatial coverage (Figure 2).

\subsection{Data on tidal elevations and currents}

To obtain a wide range of hourly data on tidal elevations and currents, the tide results simulated by the 3-D hydrodynamic FVCOM were used. In this model, the main 11 tidal constituents for both tidal elevation and tidal current were $\mathrm{M}_{2}$, $\mathrm{S}_{2}, \mathrm{~N}_{2}, \mathrm{~K}_{2}, \mathrm{~K}_{1}, \mathrm{O}_{1}, \mathrm{P}_{1}, \mathrm{Q}_{1}, \mathrm{M}_{4}, \mathrm{MS}_{4}$, and $\mathrm{MN}_{4}$. The simulated results were verified in previous studies (Xuan et al., 2016), and these results reasonably reflect the realistic tidal elevations and currents over the Yangtze Bank. The MATLAB harmonic analysis toolbox, T_Tide (Pawlowicz et al., 2002), was used to obtain the harmonic constants (amplitude $H$ and phase $g$ ) of each tidal constituent and then to predict the hourly variation of tidal elevations and currents over the Yangtze Bank on February 8, 2016.

\section{Results}

\subsection{The spatial distribution and tidal variation of TSS}

\subsubsection{The spatial distribution of TSS}

A similar spatial distribution of TSS was found over the Yangtze Bank in the eight hourly GOCI-TSS images cap- tured on February 8, 2016 (Figure 3a-3h). The images show a tongue-shaped structure and a stepwise decrease in TSS concentration from the Subei Shoal to the open sea. According to the extracted frontal outlines, two fronts of TSS over the Yangtze Bank always exist, with significant spatial gradients during the GOCI coverage period (Figure $2 b$ ). One front was located near the 20-m isobath, which we called the Near-shore Front (NF). The other front covered the majority of the Yangtze Bank between $31.3^{\circ} \mathrm{N}$ and $33^{\circ} \mathrm{N}$ (at a depth of less than $50 \mathrm{~m}$ ), which corresponds with the out-boundary of the Yangtze Bank; we called this the Bank Front (BF). The positions and shapes of the two fronts exhibited a good correlation with the bottom topography. The zigzag-shaped $\mathrm{NF}$ was generally meridional and was basically located around the $20-\mathrm{m}$ isobath. The shape of the BF was similar to the 50-m isobath, indicating an offshore extension, and its meridional and zonal coverage was approximately $3^{\circ}$ and $1.7^{\circ}$, respectively. The northeastern part of the BF coincided with the 50-m isobath. The southeastern part of the BF exhibited forward and backward movement with tidal oscillations and could reach the 50-m isobath. The southern part of the BF was in an east-west orientation and relatively straight. The northern part of the BF was also in an east-west orientation but exhibited more of a curl than the southern part. In addition, the two fronts separated the TSS over the Yangtze Bank into three sub-zones, namely the near-shore turbidity zone (shallower than $20 \mathrm{~m}$ ), the bank transition zone (within the 20-50-m isobaths), and the open sea clear zone (deeper than $50 \mathrm{~m}$ ) (Figure 3i).

\subsubsection{The tidal variation of TSS}

Compared with similar spatial structures, significant tidal variations of TSS concentration over the Yangtze Bank occurred from 08:16 to 15:16 on February 8, 2016 (Figure 3a$3 \mathrm{~h})$. The process can be roughly divided into three stages, in terms of temporal variability: the decay stage, from $08: 16$ to 10:16; the maintenance stage, from 11:16 to $13: 16$; and the growth stage, from 14:16 to $15: 16$.

(1) Decay stage, from 08:16 to 10:16 (Figure 3a-3c). The TSS concentration over the Yangtze Bank showed a drastic decline. By comparing the change in the averaged TSS
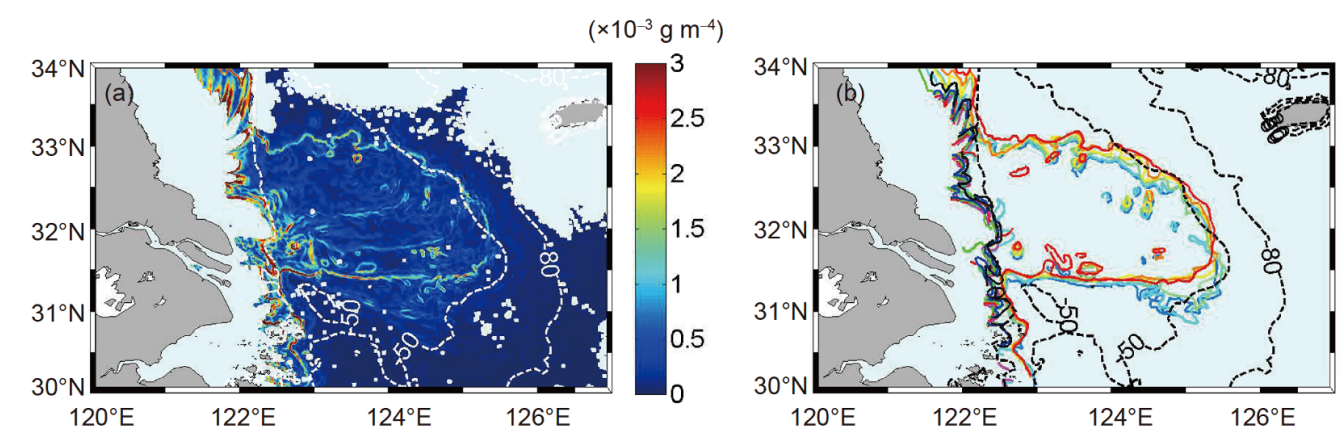

Figure 2 Gradient of TSS over the Yangtze Bank on February 8, 2016. (a) TSS gradient at 13:16, (b) hourly frontal outlines, from 09:16 to 14:16. 



Figure 3 (a)-(h) Hourly GOCI-TSS images over the Yangtze Bank from 08:16 to 15:16 on February 8, 2016, where the red solid line, blue solid line, and black solid line represent the TSS concentration of 16,32 , and $64 \mathrm{~g} \mathrm{~m}^{-3}$ respectively; the dashed lines are the isobaths. (i) The hourly variation of TSS concentration on section A (shown in Figure $3 \mathrm{a}, 32^{\circ} \mathrm{N}, 122^{\circ} \mathrm{E}-127^{\circ} \mathrm{E}$ ) from 08:16 to 15:16 and the bottom topography.

concentration in all three sub-zones from 09:16 to 10:16 (due to the limited spatial coverage at $08: 16$, these hourly data are excluded from the statistical analysis), we found that the TSS concentration decreased by $12 \%, 18 \%$, and $28 \%$ in the nearshore turbidity zone, the bank transition zone, and the open sea clear zone, respectively. Of course, the uncertainty exists that the insufficient spatial coverage of the TSS caused few data here. With the aid of the position of the TSS concentration contours (32 and $64 \mathrm{~g} \mathrm{~m}^{-3}$ ), which roughly represented the offshore and near-shore boundaries of the bank transition zone, respectively, we also found that high-turbidity waters clustered in coastal shallow waters. During the low TSS period (Figure 3c), the NF moved toward the land, and the TSS over the bank transition zone was approximately $30 \mathrm{~g} \mathrm{~m}^{-3}$. The BF position remained the same, although the TSS decreased to $16 \mathrm{~g} \mathrm{~m}^{-3}$ (Figure 3i).

(2) Maintenance stage, from 11:16 to 13:16 (Figure 3d-3f). TSS concentration over the Yangtze Bank remained stationary and reached its lowest value at 12:16 in all three zones simultaneously. The spatial distribution of TSS was relatively uniform within the three zones. The positions and shapes of the TSS concentration contours, represented by 16 , 32 , and $64 \mathrm{~g} \mathrm{~m}^{-3}$, were similar, and the position changes of the two fronts were negligible.

(3) Growth stage, from $14: 16$ to $15: 16$ (Figure $3 g-3 h$ ). TSS concentration in the bank transition zone increased by 
$72 \%$. However, due to the limitations in the spatial coverage of the GOCI-TSS data, TSS concentration in the bank transition zone could only be obtained at 15:16. The coverage area of the TSS concentration contours ( 32 and $64 \mathrm{~g} \mathrm{~m}^{-3}$ ) expanded in the offshore direction, and the high-turbidity water covered the area where the water depth was shallower than $50 \mathrm{~m}$. During this stage, the NF moved offshore, as indicated by the $64 \mathrm{~g} \mathrm{~m}^{-3}$ contour of the TSS (Figure 3h, 3i).

\subsection{Dynamic mechanism}

The Yellow and East China Seas are strong, tide-driven shelf seas, with both the horizontal currents and vertical mixing driven by periodic tides that can affect the distribution and transportation of TSS over the Yangtze Bank (Yang et al., 2007). Although the TSS over the Yangtze Bank demonstrates a similar spatial pattern during the winter, its concentration exhibits significant tidal variation (Figure 3a-3h). Therefore, we combined tidal elevations and tidal currents simulated by FVCOM to explore the dynamic mechanism of the tidal variation of TSS over the Yangtze Bank.

The magnitude and relative importance of advection and horizontal diffusion on the TSS from $08: 16$ to $15: 16$ on February 8, 2016, which were caused by tidal currents, were quantitatively estimated, according to the advection-diffusion equation of TSS (eq. (1)):

$\frac{\partial S}{\partial t}=\mathbf{V} \cdot \nabla S-\nabla \cdot G+\sum, G=\left(\overline{u^{\prime} S^{\prime}}, \overline{v^{\prime} S^{\prime}}\right)$,

where $S$ is the TSS concentration; $\mathbf{V}$ is the horizontal tidal velocity components $u, v ; u^{\prime}, v^{\prime}, S^{\prime}$ represent anomalies of $u$, $v$, and $S ; G=\left(\overline{u^{\prime} S^{\prime}}, \overline{v^{\prime}} S^{\prime}\right)$ is the diffusion flux vector in the horizontal direction; $\mathbf{V} \cdot \nabla S$ is the horizontal advection term; $-\nabla \cdot G$ is the horizontal diffusion term; and $\sum$ represents all the other terms related to the vertical, namely the vertical convection term, the vertical diffusion term, and the settling term.

The estimated results for two time intervals between 11:16 and 12:16 (Figure 4; here, only changes from 11:16 to 12:16 are shown, because the distribution in the other time intervals shows similar results) show that the horizontal advection $\mathbf{V} \cdot \nabla S$ is of order $\mathrm{O}\left(10^{-7} \mathrm{~g} \mathrm{~m}^{-3} \mathrm{~s}^{-1}\right)$, the horizontal diffusion $-\nabla \cdot G$ is of order $\mathrm{O}\left(10^{-5} \mathrm{~g} \mathrm{~m}^{-3} \mathrm{~s}^{-1}\right)$, and the local change in TSS concentration $\partial S / \partial t$ is of order $\mathrm{O}\left(10^{-3} \mathrm{~g} \mathrm{~m}^{-3} \mathrm{~s}^{-1}\right)$. In other words, compared with the local change in TSS concentration, the contribution of horizontal advection is basically negligible. During the maintenance stage, from 11:16 to $12: 16$, horizontal diffusion accounts for approximately $17 \%$ of the locate change in TSS concentration and accounts for less than $10 \%$ during the rest period. Therefore, horizontal diffusion is a secondary factor for the change in TSS concentration.

The above estimated results strongly indicate that the processes of vertical direction $\sum$, namely the vertical convection and vertical diffusion of TSS and the settlement of particles, played a key role in the tidal variation of TSS concentration during the period of observation.

Many studies on sediment migration in the Yellow and East China Seas (Jago et al., 1993; Shi et al., 2011; Choi et al., 2012; Doxaran et al., 2014; Luo et al., 2017; Azhikodan and Yokoyama, 2018) confirmed that the changes in bottom shear stress and tide-induced mixing caused by the cyclical motion of the tidal current are the main factors causing the
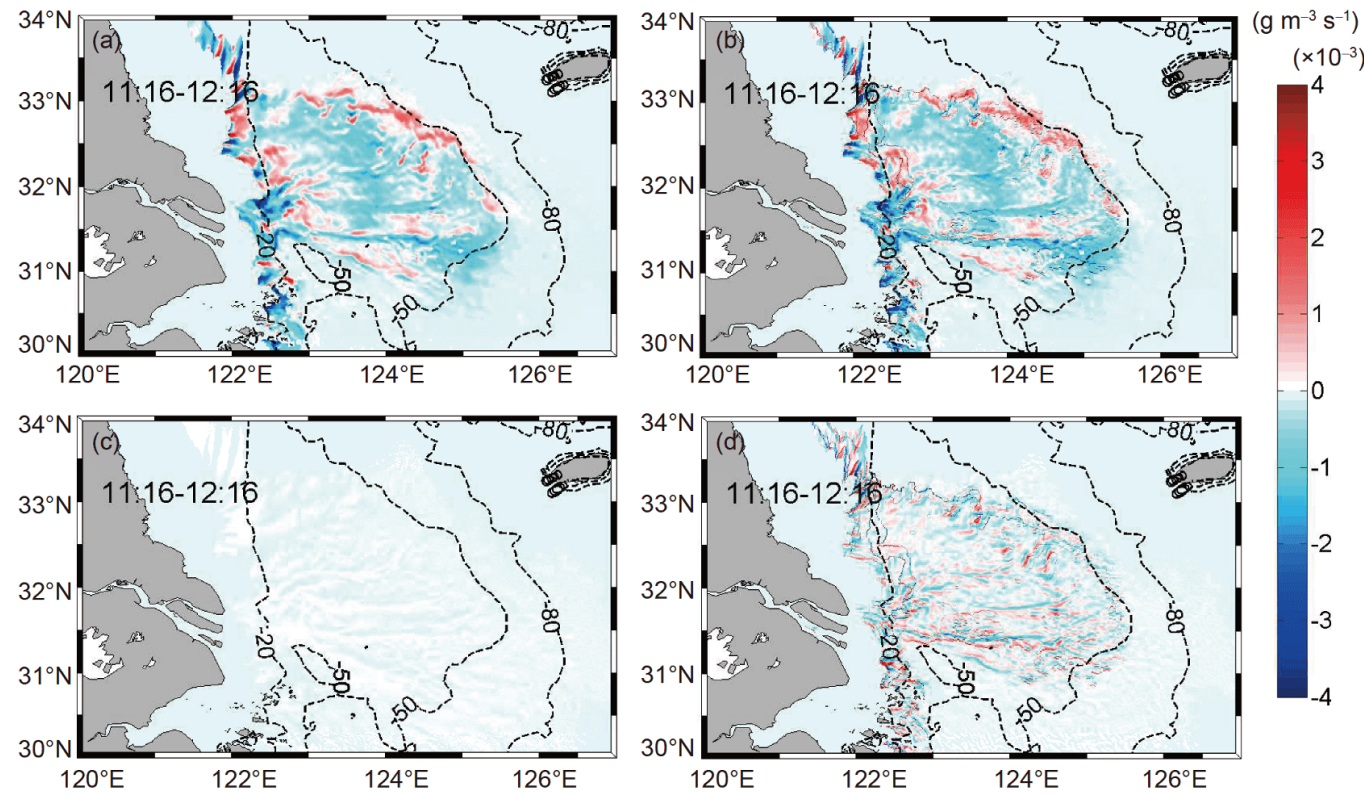

Figure 4 (a) The local change in TSS concentration $\partial S / \partial t$. (b) All terms related to vertical $\sum$. (c) The horizontal advection term $\mathbf{V} \cdot \nabla S$. (d) The horizontal diffusion term $-\nabla \cdot G$, from $11: 16$ to $12: 16$ on February $8,2016$. 
short-term variation of surface TSS in near-shore areas. To explore the relationship between the intensity of tidal mixing and the TSS over the Yangtze Bank, we used the tidal mixing parameter, $k=\log \left(H / U^{3}\right)$, which was proposed by Simpson and Hunter (1974). The location of the tidal fronts can be roughly indicated in terms of $k$, where $U=\sqrt{u^{2}+v^{2}}$ is the magnitude of tidal current velocity; $H=h+h^{\prime}$ is the water depth, $h$ represents the water depth below mean sea level, and $h^{\prime}$ represents tidal elevation. Simpson and Hunter used the amplitude of tidal currents as the characteristic velocity $U$ to estimate the overall (averaged) effect of tidal currents. However, using the amplitude of tidal currents ignores shortterm variations in the intensity of tidal mixing caused by tidal motion; therefore, when it is extended to the study of shortterm variations in tidal mixing, such as tidal variation in this study, the magnitude of tidal current velocity is required, and this extension has been applied (Ni et al., 2016). The tidal mixing parameter $k$ indicates that the change in the intensity of tidal mixing caused by periodic tidal motion is the result of the combined effects of water depth $H$ and tidal current $U$. A smaller tidal mixing parameter $k$ represents a stronger tidal mixing or a shallower water depth. The spatial distribution of TSS exhibits a good correlation with the tidal mixing parameter (Figure 5), the low (high) tidal mixing parameter $k$ corresponds to the high (low) TSS concentration, and the tidal mixing parameter $k$ generally increases offshore (Figure
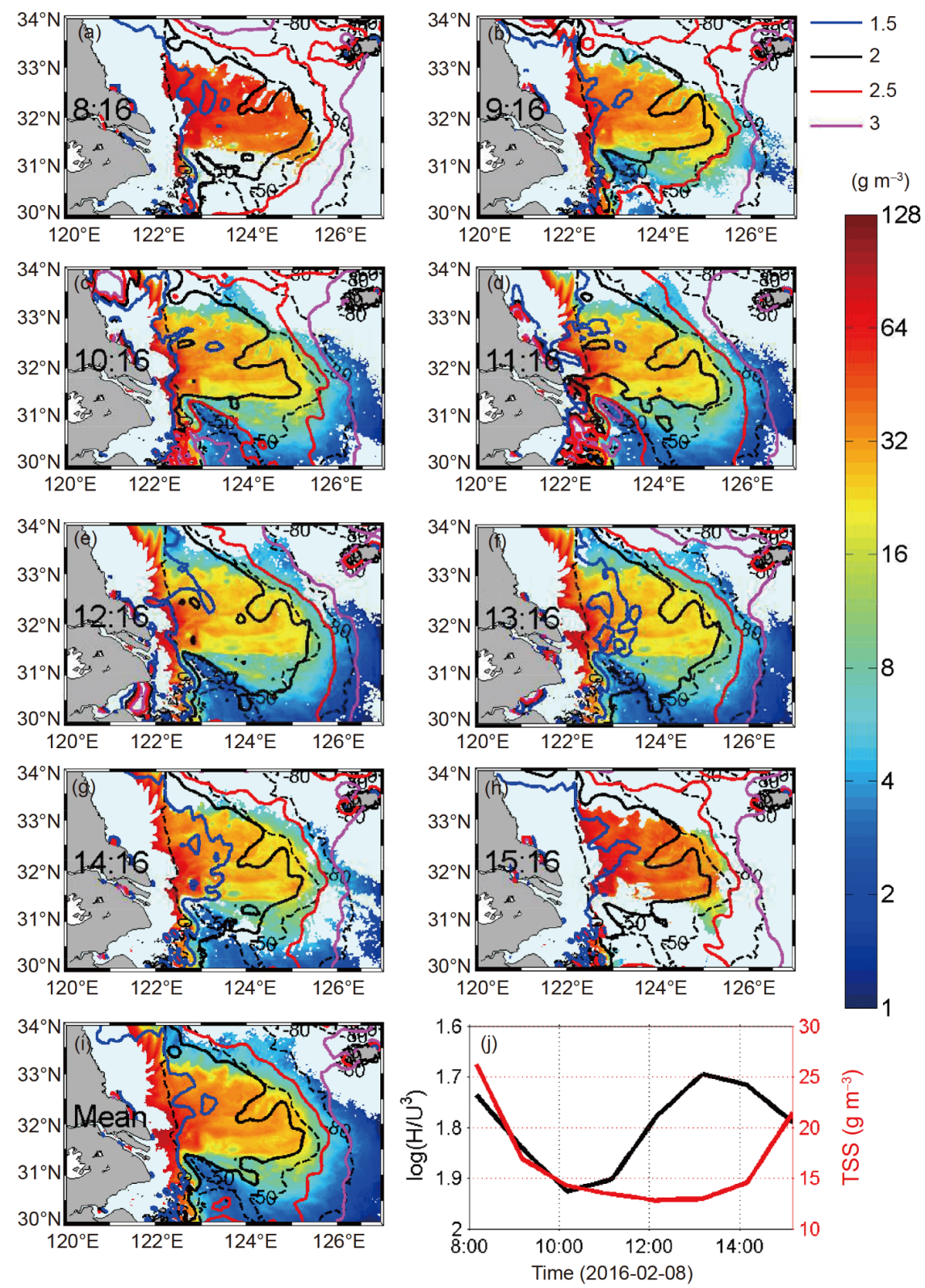

Figure 5 (a)-(h) Hourly tidal mixing parameter $k$ (contour) superposed on TSS (filled color) from 08:16 to 15:16 on February 8, 2016. (i) Averaged tidal mixing parameter (contour) superposed on averaged TSS (filled color). (j) The change in regional averaged tidal mixing parameter and regional averaged TSS concentration from 08:16 to 15:16 on February 8, 2016. 
$5 \mathrm{a}-5 \mathrm{i})$. The spatial pattern of the tidal mixing parameter contours (blue line $k=1.5$ and black line $k=2$ ) are similar to the isobaths (20 and $50 \mathrm{~m}$ ) and correspond approximately to the NF and BF. These results strongly suggest that the spatial distribution of TSS over the Yangtze Bank forms a relatively stable tongue-shaped structure that decreases stepwise offshore, which is related to the spatial distribution of the tidal mixing intensity and dominated by spatially varying bottom topography.

At the same time, the intensity of the tidal mixing also indicates a significant tidal variation (Figure 5a-5h). The overall distribution of the hourly tidal mixing parameter $k$ is similar to that of the averaged distribution (Figure 5i), which increases offshore but still pulsates. The contours expand toward the open sea, shrink toward the coast with tidal oscillations, and also show bending and deformation, indicating that the intensity of tidal mixing over the Yangtze Bank strengthened or weakened in varying degrees, resulting in significant tidal changes to TSS concentration. However, the changes in TSS concentration and the intensity of tidal mixing are not completely synchronous (Figure $5 \mathrm{j}$ ). For example, the tidal mixing parameter $k$ reaches a maximum value of 1.93 at 10:16 (the weakest mixing intensity), while the TSS concentration reaches a minimum value of $12.8 \mathrm{~g} \mathrm{~m}^{-3}$ at 12:16. TSS lags by about two hours relative to the intensity of tidal mixing, because it takes time for the bottom sediment to resuspend and diffuse to the surface through vertical mixing, and the length of the lag time is related to the water depth and the intensity of the tidal mixing (Yang et al., 2007). Through the above discussion, we find that the spatial distribution of TSS over the Yangtze Bank is mainly related to the distribution of tidal mixing intensity, which is dominated by the bottom topography, while the tidal variation of TSS concentration is primarily related to the change in tidal mixing intensity affected by the magnitude of tidal current velocity $U$ and water depth $H$.

Questions on the relative importance of $U$ and $H$ on the tidal mixing intensity, and where and when it takes place, can be answered by calculating the material derivative of the tidal mixing parameter $k=\log \left(H / U^{3}\right)$, as follows:

$$
\begin{aligned}
\frac{\mathrm{d} \log \left(H / U^{3}\right)}{\mathrm{d} t}= & \frac{1}{H \ln 10} \frac{\partial H}{\partial t}+\frac{1}{H \ln 10} \mathbf{V} \cdot \nabla H \\
& -\frac{3}{U \ln 10} \frac{\partial U}{\partial t}-\frac{3}{U \ln 10} \mathbf{V} \cdot \nabla U
\end{aligned}
$$

which can be separated into local variation terms $\left(\frac{1}{H \ln 10} \frac{\partial H}{\partial t},-\frac{3}{U \ln 10} \frac{\partial U}{\partial t}\right) \quad$ and $\quad$ advection terms $\left(\frac{1}{H \ln 10} \mathbf{V} \cdot \nabla H,-\frac{3}{U \ln 10} \mathbf{V} \cdot \nabla U\right)$ of $H$ and $U$ respectively.

The results in Figure 6 show that the hourly variation of tidal mixing intensity is mainly caused by the local variation of the tidal current (Figure 6b) followed by the advection of the tidal current $U$ (Figure 6d) and that the variation caused by the change in water depth $H$ only works in shallow coastal water, where the depth is less than $20 \mathrm{~m}$ (Figure 6a and 6c). It is highly likely that the change in tidal mixing intensity caused by the cyclical motion of the tidal current is the main factor for the tidal variation of TSS concentration over the Yangtze Bank. It should be noted that, in this paper, only changes from 08:16 to 09:16 are taken as an example; the distribution in other periods show similar results.
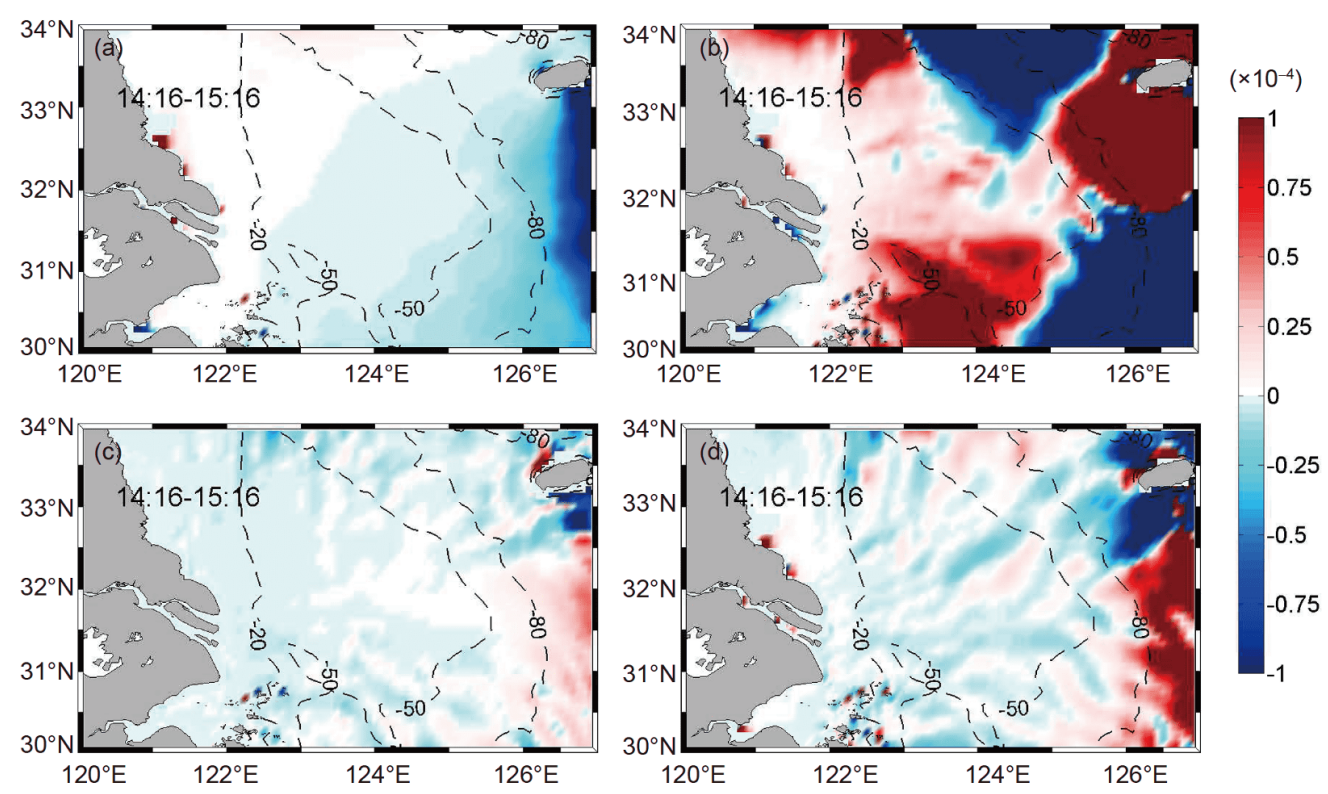

Figure 6 The material derivative of the tidal mixing parameter, $\frac{\mathrm{d} \log \left(H / U^{3}\right)}{\mathrm{d} t}$ the local variation terms: $\frac{1}{H \ln 10} \frac{\partial H}{\partial t}(\mathrm{a}),-\frac{3}{U \ln 10} \frac{\partial U}{\partial t}(\mathrm{~b})$; the advection terms: $\frac{1}{H \ln 10} \mathbf{V} \cdot \nabla H(\mathrm{c}),-\frac{3}{U \ln 10} \mathbf{V} \cdot \nabla U(\mathrm{~d})$ from $08: 16$ to $09: 16$ on February $8,2016$. 


\section{Discussion and conclusions}

The process of TSS tidal variation over the Yangtze Bank was examined based on hourly images captured by the GOCI. Previous studies lacked spatial characterization and dynamic analysis of tidal variation, due to limitations in the spatio-temporal resolution of the observation data. In this study, the spatial pattern and tidal variation characteristics of TSS over the Yangtze Bank are described in detail, and its dynamic mechanism is analyzed in combination with the simulated tidal currents and tidal elevation from the 3-D hydrodynamic FVCOM. The hourly GOCI-TSS images of the Yangtze Bank show a similar tongue-shaped spatial structure, which decreases offshore in a stepwise manner. The TSS is separated by two fronts over the Yangtze Bank and then into three sub-zones: the near-shore turbidity zone, the bank transition zone, and the open sea clear zone. From a time perspective, significant tidal variations in TSS concentration exist, and the process during the observation period can be divided into three stages: decay, maintenance, and growth. Although the GOCI-TSS data failed to form a complete tidal cycle of $12.4 \mathrm{~h}$, the $7 \mathrm{~h}$ continuous data are able to reflect the tidal variation of TSS, due to the symmetrical nature of the tidal cycle.

In this study, we found that the spatial distribution of TSS over the Yangtze Bank is related to the spatial distribution of the tidal mixing intensity, which is dominated by the bottom topography and tidal currents. The increasing offshore water depth causes the tide-induced mixing intensity and TSS concentration to decrease, forming a tongue-shaped structure. At the same time, the tidal variation of TSS concentration is mainly caused by periodic changes to the tideinduced mixing intensity, which is dominated by the cyclical motion of the tidal current. TSS concentration exhibits a lag of approximately two hours relative to the change in the tideinduced mixing intensity.

The tidal variation of surface TSS was captured by the GOCI-TSS images. From the perspective of tidal mixing, only the tidal currents and elevations simulated by FVCOM were used to analyze the dynamic mechanism in this study. It is worth noting that the bottom sediment is resuspended by shear stress and diffuses to the surface through tidal mixing; however, this vertical migration process of TSS in sea water was not simulated. To better understanding the process, further research is needed, with the help of a hydrodynamic model that incorporates a sediment module. In addition, shearing and vertical mixing caused by the wind in nearshore shallow waters are also strong dynamic factors causing sediment resuspension (Bian et al., 2013). Violent atmospheric processes, such as typhoons and strong winter storms, can cause a drastic increase in TSS concentration over a short time period (Yang et al., 2007; Bian et al., 2010). Generally, the bottom shear stress caused by the wind is much less than that caused by the tidal current ( $\mathrm{Lu}$ et al., 2011); therefore, in this study, only the tidal current, tidal elevation, and bottom topography were considered when examining the impact on spatial distribution and tidal variations of TSS over the Yangtze Bank. The impact of wind fields on the short-term variation of TSS over the Yangtze Bank can be further explored in combination with atmospheric models in the future. Our analysis enhances our understanding of the short-term changes to TSS in the Yellow and East China Seas, and it provides an observational basis for the numerical study of sediment transportation and resuspension over the Yangtze Bank.

Acknowledgements We are thankful for the GOCI data provided by the Korea Ocean Satellite Center (http://kosc.kiost.ac.kr/eng/). This work was supported by the National Key Research \& Development Program of China (Grant No. 2016YFC1401603), the NSFC-Zhejiang Joint Fund for the Integration of Industrialization and Informatization (Grant No. U1609201) and the National Natural Science Foundation of China (Grant No. 41621064).

\section{References}

Azhikodan G, Yokoyama K. 2018. Sediment transport and fluid mud layer formation in the macro-tidal Chikugo river estuary during a fortnightly tidal cycle. Estuar Coast Shelf Sci, 202: 232-245

Bian C, Jiang W, Song D. 2010. Terrigenous transportation to the Okinawa Trough and the influence of typhoons on suspended sediment concentration. Cont Shelf Res, 30: 1189-1199

Bian C, Jiang W, Quan Q, Wang T, Greatbatch R J, Li W. 2013. Distributions of suspended sediment concentration in the Yellow Sea and the East China Sea based on field surveys during the four seasons of 2011. J Marine Syst, 121-122: 24-35

Chen S. 2001. Seasonal, neap-spring variation of sediment concentration in the joint area between Yangtze Estuary and Hangzhou Bay. Sci China Ser B-Chem, 44: 57-62

Choi J K, Park Y J, Ahn J H, Lim H S, Eom J, Ryu J H. 2012. GOCI, the world's first geostationary ocean color observation satellite, for the monitoring of temporal variability in coastal water turbidity. J Geophys Res, 117: C09004

Choi J K, Park Y J, Lee B R, Eom J, Moon J E, Ryu J H. 2014. Application of the geostationary ocean color imager (GOCI) to mapping the temporal dynamics of coastal water turbidity. Remote Sens Environ, 146: 24-35

Doxaran D, Lamquin N, Park Y J, Mazeran C, Ryu J H, Wang M, Poteau A. 2014. Retrieval of the seawater reflectance for suspended solids monitoring in the East China Sea using MODIS, MERIS and GOCI satellite data. Remote Sens Environ, 146: 36-48

Jago C F, Bale A J, Green M O, Howarth M J, Jones S E, Mccave I N, Millward G E, Morris A W, Rowden A A, Williams J J. 1993. Resuspension processes and seston dynamics, Southern North Sea. Philos Trans R Soc B-Biol Sci, 343: 475-489

Klemer A, Barko J. 1991. Effects of mixing and silica enrichment on phytoplankton seasonal succession. Hydrobiologia, 210: 171-181

Lu J, Qiao F L, Wang X H, Wang Y G, Teng Y, Xia C S. 2011. A numerical study of transport dynamics and seasonal variability of the Yellow River sediment in the Bohai and Yellow Seas. Estuar Coast Shelf Sci, 95: 3951

Luo Z, Zhu J, Wu H, Li X. 2017. Dynamics of the sediment plume over the Yangtze Bank in the Yellow and East China Seas. J Geophys ResOceans, 122: 10073-10090

Milliman J D, Meade R H. 1983. World-wide delivery of river sediment to 
the oceans. J Geol, 91: 1-21

Mutshinda C M, Finkel Z V, Irwin A J. 2013. Which environmental factors control phytoplankton populations? A Bayesian variable selection approach. Ecol Model, 269: 1-8

Ni X, Huang D, Zeng D, Zhang T, Li H, Chen J. 2016. The impact of wind mixing on the variation of bottom dissolved oxygen off the changjiang estuary during summer. J Marine Syst, 154: 122-130

Pawlowicz R, Beardsley B, Lentz S. 2002. Classical tidal harmonic analysis including error estimates in MATLAB using T_TIDE. Comput Geosci, 28: 929-937

Qiao S, Shi X, Wang G, Zhou L, Hu B, Hu L, Yang G, Liu Y, Yao Z, Liu S. 2017. Sediment accumulation and budget in the Bohai Sea, Yellow Sea and East China Sea. Mar Geol, 390: 270-281

Ryu J H, Han H J, Cho S, Park Y J, Ahn Y H. 2012. Overview of geostationary ocean color imager (GOCI) and GOCI data processing system (GDPS). Ocean Sci J, 47: 223-233

Saito Y, Yang Z S. 1995. Historical change of the Huanghe (Yellow River) and its impact on the sediment budget of the East China Sea. Yokohama: Proceedings of International Symposium on Global Fluxes of Carbon and its Related Substances in the Coastal Sea-Ocean-Atmosphere System. 7-12

Shi W, Wang M. 2010. Satellite observations of the seasonal sediment plume in central East China Sea. J Marine Syst, 82: 280-285
Shi W, Wang M, Jiang L. 2011. Spring-neap tidal effects on satellite ocean color observations in the Bohai Sea, Yellow Sea, and East China Sea. J Geophys Res, 116: C12032

Simpson J H, Hunter J R. 1974. Fronts in the Irish Sea. Nature, 250: 404 406

Xuan J, Yang Z, Huang D, Wang T, Zhou F. 2016. Tidal residual current and its role in the mean flow on the Changjiang Bank. J Marine Syst, 154: 66-81

Yang Z, Lei K, Guo Z, Wang H. 2007. Effect of a winter storm on sediment transport and resuspension in the distal mud area, the East China Sea. J Coast Res, 232: 310-318

Yin W, Huang D. 2016. Evolution of submesoscale coastal frontal waves in the East China Sea based on geostationary ocean color imager observational data. Geophys Res Lett, 43: 9801-9809

Yuan D, Zhu J, Li C, Hu D. 2008. Cross-shelf circulation in the Yellow and East China Seas indicated by MODIS satellite observations. J Marine Syst, 70: 134-149

Yuan D, Hsueh Y. 2010. Dynamics of the cross-shelf circulation in the Yellow and East China Seas in winter. Deep-Sea Res Part II-Top Stud Oceanogr, 57: 1745-1761

Zhou Z X, Yu R C, Zhou M J. 2017. Seasonal succession of microalgal blooms from diatoms to dinoflagellates in the East China Sea: A numerical simulation study. Ecol Model, 360: 150-162

(Responsible editor: Shouye YANG)

Open Access This article is distributed under the terms of the Creative Commons Attribution 4.0 International License (http://creativecommons.org/licenses/ by/4.0/), which permits use, duplication, adaptation, distribution and reproduction in any medium or format, as long as you give appropriate credit to the original author(s) and the source, provide a link to the Creative Commons license and indicate if changes were made. 